\title{
Why I . . . do triathlons
}

\section{Cancer specialist Lucy Gossage tells Adrian O'Dowd why taking time away from her clinical work to be a professional triathlete has made her a better doctor}

\section{Adrian O’Dowd}

London, UK

Sometimes, taking the scenic route during a career can help remind you why being a doctor is such a good occupation, says cancer specialist Lucy Gossage.

Gossage is an oncology consultant at Nottingham University Hospitals NHS Trust. She is also a successful triathlete with multiple Ironman championship wins to her name.

Her involvement with triathlons came from a simple dare, but has had a significant impact on her health and wellbeing. "I entered my first triathlon as a dare after a long term relationship ended," she explains. "At that time, I would have laughed at the thought of racing professionally, though I did better than I expected."

Gossage worked full time as an oncology specialist registrar until 2009 when she moved to Cambridge to start a doctorate. She initially found the adjustment hard which motivated her to train more seriously for events.

"I really struggled for the first year with not seeing patients. I had no job satisfaction and felt unsupported. So I started to train a bit harder rather than just exercising," she explains.

This eventually led her to becoming a professional athlete. "As my studies improved I also got better at triathlons. Half way through I got my pro licence, so I decided it was now or never," Gossage says. "At the end of 2011, I went part time (60\%) doing my doctorate and continued racing professionally. When I finished my studying in 2014, I took two and a half years out of programme to be a professional triathlete."

Gossage acknowledges she was lucky to be able to take this route. "When you work in oncology, you realise that life is short and you only get one shot," she says. "I was lucky that my deanery supported that and allowed me to take some time out."

She was very successful as a full time triathlete, winning 12 Ironman races, twice finishing in the top 10 at the Ironman world championships, and receiving various accolades including British Triathlon elite long distance triathlete of the year twice. "I made more money from triathlons than I would have as a doctor, so it wasn't just a hobby," she says.
It was, however, never a long term career choice for her. "I always intended to return to medicine," Gossage says. "As a full time athlete, you travel the world and the good days are incredible. But it's tedious training five or six hours a day, every day. It also felt like a very selfish pursuit-your only focus is getting quicker. It's different from being a doctor; I loved it, but it was only ever a hiatus in my life."

Since returning to clinical work in 2016, Gossage has continued to race, but this will be her last year racing professionally. "I now work three days a week as I need time for other things such as doing talks and my 5K Your Way, Move Against Cancer charity initiative," she says (www.5kyourway.org).

The charity, which Gossage cofounded last year, is a community based initiative which encourages people affected by cancer and those working in cancer services to walk, jog, run, cheer, or volunteer at a local parkrun event on the last Saturday of every month.

"I cofounded it with Gemma Hillier-Moses who had cancer when she was 24," explains Gossage. "We started in Nottingham but the idea grew and we've now got over 50 groups around the country."

The triathlete bug seems to have inspired some of Gossage's colleagues, such as the professor of oncology in Nottingham who recently did his first triathlon. " $5 \mathrm{~K}$ Your Way has been good at inspiring some staff to start running, but I also get messages on social media from junior doctors who are also interested in my work-life balance," she says.

"I genuinely think taking time out for triathlons has made me a better doctor, not least because it taught me to be clear about what I want from life."

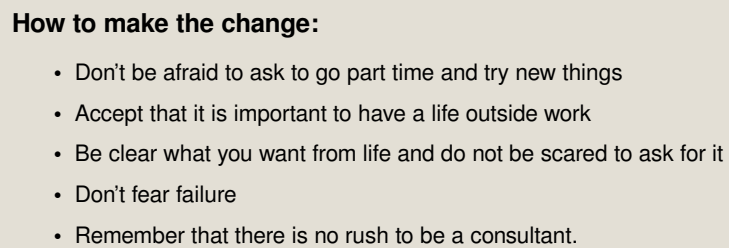

